
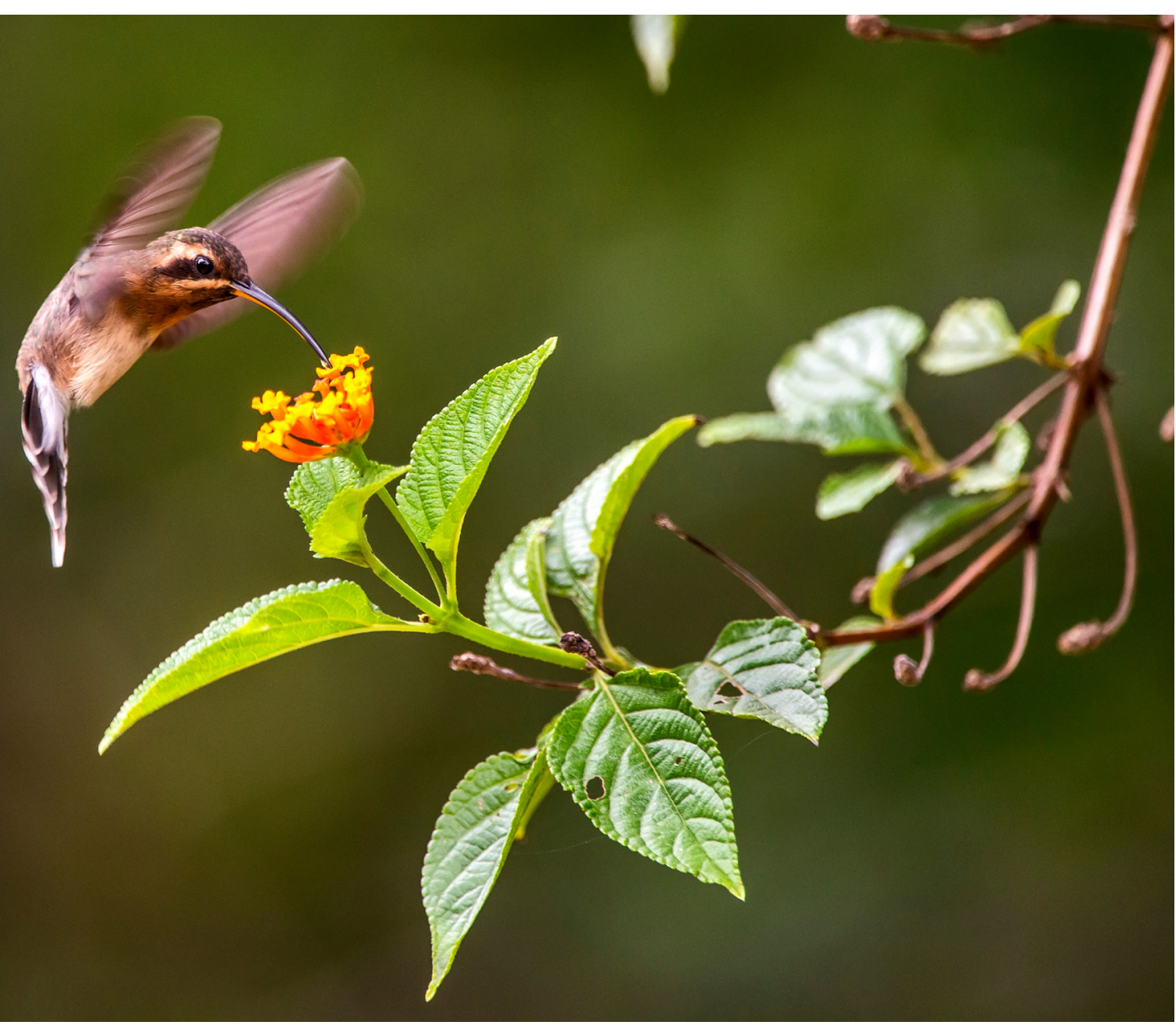


\section{Grupos de Promoção em Saúde no Ensino Fundamental com Enfoque no Uso de Álcool e Outras Drogas}

Health Promotion Groups In Primary Education Focusing On The Use Of Alcohol And Other Drugs

\section{Resumo}

A Extensão Universitária promove a aproximação da Universidade com a comunidade, contribuindo com o desenvolvimento dos discentes envolvidos e a comunidade. O objetivo do artigo é descrever e discutir a experiência extensionista de estudantes de psicologia da Universidade do Estado de Minas Gerais em um projeto de promoção em saúde, com foco no uso de álcool e outras drogas, com alunos do $9^{\circ}$ ano do ensino fundamental, com idade variando entre 12 e 15 anos de idade. Caracteriza-se como um estudo qualitativo na modalidade de relato de experiência, em que foram realizados grupos operativos em uma escola pública de uma cidade do interior de Minas Gerais. Os encontros ocorreram ao longo de quatro meses, de agosto a novembro de 2017, com encontros quinzenais. Os temas e as técnicas utilizadas foram diversificados, com foco na captação do interesse e atenção dos adolescentes. Os temas eram escolhidos pelos próprios adolescentes ao final de cada encontro. Foram abordados temas como violência, preconceito, respeito e o uso de álcool e outras drogas. As técnicas utilizadas foram desde rodas de conversa até o uso de técnicas teatrais. O projeto atingiu seu propósito de despertar o interesse dos alunos quanto a temas muitas vezes considerados tabus e dar voz a suas dúvidas e questionamentos.

Palavras-chave: Promoção da saúde. Saúde escolar. Adolescente. Álcool e drogas
Victor Gabriel souza Faria* Bianca de Freitas Moraes Camila souza de Almeida Universidade do Estado de Minas Gerais (UEMG) E-mail:victorgsf97@gmail.com* 


\section{Abstract}

The University extension brings the University closer to the community, contributing to the development of the students involved and the community. The purpose of this article is to describe and discuss the extensionist experience of psychology students at the State University of Minas Gerais in a health promotion project focusing on the use of alcohol and other drugs, with students from the 9th grade, with age ranging from 12 to 15 years of age. It is characterized as a qualitative study in the modality of experience reporting, in which operating groups were performed in a public school in a city in the interior of Minas Gerais. The meetings took place over four months, from August to November 2017, with biweekly meetings. The themes and techniques used were diversified, focused on capturing the interest and attention of adolescents. The themes were chosen by the adolescents themselves at the end of each meeting. Subjects such as violence, prejudice, respect and the use of alcohol and other drugs were addressed. The techniques used were from talk wheels to the use of theatrical techniques. The project achieved its purpose of arousing the interest of the students in the subjects often considered taboos and to give voice to their doubts and questions.

Key words: Health promotion. School health. Teenager. Alcohol and drugs 


\section{INTRODUÇÃO}

A extensão Universitária é a relação que se estabelece entre os acadêmicos de um curso e a comunidade em que estão inseridos, sendo um dos pilares da Universidade, pois consegue desenvolver o senso crítico dos alunos envolvidos, capacitando-os para a realidade pós-universidade e devolve para a comunidade os conhecimentos que muitas vezes ficam restritos à comunidade acadêmica (DUARTE, 2014).

Uma das atividades de extensão desafiadoras e necessárias são aquelas realizadas com adolescentes, pois esses se encontram em um estágio de desenvolvimento não apenas físico, mas cognitivo e comportamental intenso, marcado pelas experimentações e comportamentos de riscos. E durante esta fase o jovem, muitas vezes, acaba se encontrando em situações e cenários onde está sujeito à violência e ao uso das drogas (FARIA FILHO, 2015). Diante disto surge a necessidade da realização de atividades que possam esclarecer dúvidas e promover hábitos saudáveis, sempre dando voz e espaço a esses jovens.

Sabe-se que um dos grandes desafios existentes é trabalhar o tema do uso de álcool e outras drogas, tanto por ser um tabu quanto pela dificuldade na abordagem do tema sem a conotação de moralismo ou punição. Mas o assunto deve ser abordado, pois o uso de drogas na adolescência está relacionado ao aumento da violência, das doenças mentais, da gravidez e de doenças sexualmente transmissíveis (MALTA et al, 2014). O consumo destas drogas está muitas vezes relacionado a experiências aversivas durante a infância (GONÇALVES et al, 2016), e com condições relacionadas ao nível socioeconômico, à rede social e à escola (MALTA et al, 2014; LOCATELLI et al, 2014).

Dados apontam que as taxas de uso de álcool e outras drogas são significativas na adolescência e com crescimento acentuado no uso de álcool por adolescentes do sexo feminino. Um estudo realizado pelo IBGE (2016) mostra que no último mês 23,8\% dos adolescentes brasileiros fizeram uso de bebidas alcoólicas, sendo a prevalência nos meninos de $22,5 \%$ e nas meninas de $25,1 \%$. A pesquisa ainda mostrou que 55,5\% dos escolares do 90 ano do ensino fundamental já haviam experimentado álcool na vida. Sobre o uso de outras drogas tem-se que 4,1\% dos estudantes do 90 ano do ensino fundamental fizeram uso nos 30 dias anteriores à data da pesquisa (IBGE, 2016).

Ao se pensar no crescimento do uso de álcool e outras drogas por adolescentes, a escola deve ser uma das prioridades para o investimento em projetos, já que o adolescente passa a maior parte do seu dia envolvido com as atividades do local. Estudos apontam que estudar em período noturno aumentaria em até 3,8 vezes as chances de experimentação de drogas, faltar frequentemente às aulas, queda do rendimento escolar e a evasão também seriam fatores de risco ou predisponentes ao uso de drogas (MALTA et al, 2014; CARDOSO; MALBERGIER, 2014).

Já o bom rendimento escolar, ter a supervisão dos pais / responsáveis acerca das tarefas escolares e faltar pouco às aulas são considerados fatores protetores (CARDOSO; MALBERGIER, 2014). Por isso a importância de se abordar a temática na 
escola. O grande desafio para educadores, no entanto, é o como abordar. Quais os limites? E como realmente traçar um diálogo com esses adolescentes?.

Projetos relacionados à temática do uso de álcool e outras drogas com adolescentes, podem não alcançar seus objetivos de prevenção do uso quando são realizados de forma ampla, tentando abranger vários temas ao mesmo tempo ou apenas com repasse de informações sobre o que seriam as drogas (STRØM et al, 2015). Já projetos com enfoques menos amplos, que trazem temáticas mais pontuais, como a discussão de temas relacionados à promoção de hábitos de vida saudável, podem ser mais efetivos do que apenas o repasse de informações gerais sobre os malefícios do uso de álcool e outras droga (BARROSO; MENDES; BARBOSA, 2013).

Porém, há diversas dificuldades que podem ser encontradas ao se trabaIhar com a promoção da saúde sobre drogas no ambiente escolar. Algumas dessas dificuldades são as representações sociais que associam o consumo à violência, a responsabilização e culpabilização da família, a falta de conhecimento acerca dos aspectos da relação humano-substância, a fragilidade da rede de apoio, dentre outros (FARIA FILHO, 2015).

Um dos recursos que pode auxiliar na discussão do assunto em sala de aula e vencer os obstáculos das representações sociais que cada indivíduo carrega, incluindo os professores, é o grupo operativo, recurso que promove aprendizagem através de uma visão crítica da realidade. Os grupos operativos se encontram de acordo com os conceitos de promoção da saúde que enfocam no empoderamento e autonomia dos indivíduos (VINCHA; SANTOS; CERVATO-MANCUSO, 2017).

Nesse sentido, a relevância do estudo recai na possibilidade de disseminar a experiência de trabalho com grupos operativos com adolescentes de escolas públicas, contribuindo para o avanço na melhoria da qualidade de vida deste grupo populacional.

Nessa perspectiva, este estudo foi realizado com o objetivo de descrever ações realizadas em uma escola pública com alunos do $9 \circ$ ano do ensino fundamental sobre o tema promoção da saúde e uso de álcool e outras drogas. O Projeto é oriundo do Programa Institucional de Apoio à Extensão (PAEx) da Universidade do Estado de Minas Gerais (UEMG).

\section{MÉTODO}

Trata-se de um estudo descritivo de natureza qualitativa na modalidade de relato de experiência, vivenciado por dois discentes do curso de psicologia. Ambos cursavam o quarto período e tinham experiência prévia na realização de grupos operativos. Um dos alunos participantes era bolsista PAEx.

O projeto de extensão ocorreu em uma escola pública estadual de uma cidade do centro- oeste mineiro, com alunos do $9^{\circ}$ ano do ensino fundamental. Os encontros ocorreram quinzenalmente no período de agosto a novembro de 2017, perfazendo o total de dez encontros com tempo médio de 50 minutos cada.

A turma em que foi realizado o projeto contava com 28 alunos e por se tratar 
de uma turma do 9o ano do ensino fundamental a faixa etária variou de 13 a 15 anos de idade. Todos os estudantes participaram dos encontros, e aqueles que não desejassem no dia realizar a atividade permaneciam em sala de aula como espectador.

A escola em questão se localiza em um bairro periférico da cidade. A escolha do local ocorreu porque a pesquisadora responsável já havia realizado pesquisa anterior sobre o uso de álcool e outras drogas com os alunos e o índice foi considerado significativo, além de ter sido uma demanda da própria escola. Assim, com o intuito de estreitar o vínculo e aumentar o conhecimento dos alunos sobre a temática foram realizados os grupos operativos.

Os encontros ocorreram em horário de aula, sendo que quinzenalmente era escolhido um dia da semana diferente para não trazer prejuízo de conteúdo aos alunos. O tema inicial abordado foi "O que é ser adolescente?". Havia uma agenda planejada e aprovada pela coordenação da escola, mas ao se realizar o primeiro grupo operativo observou-se que era necessário trabalhar com base nas inquietudes dos adolescentes, pois com a discussão sobre "O que é ser adolescente?" questões referentes a preconceito, autoestima e convívio na escola apareceram como fortes questões, indo além do planejado pelos pesquisadores. Pensou-se também que ao se deixar a agenda de encontros abertas a sugestões, a atenção dos jovens seria mais facilmente captada, pois seriam temas surgidos de suas inquietações, vivências e dúvidas.

Todos os grupos operativos iniciavam com atividades de respiração e concentração, seguidas por uma dinâmica e logo após era abordado o tema do dia. Foram utilizadas várias técnicas para a sua realização, desde rodas de conversa, discussão em pequenos grupos, técnicas teatrais e desenhos.

O projeto foi aprovado pelo PAEX, edital 01/2017, número de cadastro 4431/2017, Universidade do Estado de Minas Gerais.

\section{RESULTADOS}

Inicialmente o projeto visava à realização de grupos operativos voltados para a temática do uso de álcool e outras drogas, mas após o primeiro grupo notou-se ser necessário um processo de aproximação com a temática relacionada ao uso de álcool e outras drogas, sendo abordados temas mais relacionados aos conflitos inerentes ao adolescente, como estudos, perspectivas futuras e autoestima nos primeiros encontros, para depois introduzir o tema do uso de drogas.

Em discussões realizadas com a equipe pedagógica da escola e nas observações notou-se a necessidade de abordar temas como a realidade dos adolescentes, incluindo o que significava a escola para esses, assim como questões relacionadas a bullying, respeito e perspectivas para o futuro, para só depois abordar o tema do uso de drogas.

Foram ao todo dez encontros. Inicialmente trabalhou-se os temas relacionados à relação aluno- aluno, logo depois aluno-escola, aluno-sociedade e o indivíduo como adolescente e suas percepções. Apenas nos três últimos encontros foram
A pesquisa citada está em fase de conclusão e é parte do doutorado da pesquisadora

coordenadora, a pesquisa foi realizada com escolares do $9^{\circ}$ ano do ensino fundamental de escola públicas e privadas e traz como dado preliminar a experimentação por 50,3\% da amostra, o uso de drogas ilícitas na vida foi de 7,7\% na amostra. Na escola em questão a experimentação de álcool foi significativa, assim tiveram alunos que relataram o uso de drogas ilícitas. 
abordados os temas relacionados ao uso de álcool e outras drogas, pois se considera que o tema não deve ser trabalhado de forma aleatória, mas sim, entrelaçado a um contexto mais amplo.

Mudanças de comportamento ou a sua possibilidade foram pontos centrais do projeto, uma vez que é necessário que fique clara a possibilidade de reelaboração do lugar do adolescente na escola, na família e consigo próprio (BARROSO; MENDES; BARBOSA, 2013).

O formato dos grupos operativos e os instrumentos utilizados foram múltiplos e se deu de acordo com a demanda de cada tema e da percepção das necessidades dos adolescentes. Foram utilizadas colagens, confecção de cartazes, rodas de discussão e até mesmo expressão corporal e técnicas teatrais.

O primeiro encontro trabalhou "O que é ser adolescente?", no qual se utilizou colagens e fabricação de cartazes para discutir o tema. A sala foi dividida em grupos e esses apresentaram a produção ao final. O "Ser adolescente" foi relacionado a estudar, ir a festas, estar com os amigos e comprar itens da moda, mas também foram relatados o risco do uso de drogas, a gravidez na adolescência e escolhas como qual o curso a fazer na universidade.

O segundo encontro trabalhou a relação escola - aluno. Nesse foi proposto um trabalho grupal em que os adolescentes deveriam realizar um único cartaz sobre a realidade na escola e suas perspectivas. O grupo demonstrou dificuldades em se trabalhar como um único grupo, e o resultado final mostrou a escola como local de aprendizado, mas com muitas regras; relataram certo desânimo com as aulas e tarefas, além da pressão dos pais para continuarem a estudar.

Os próximos dois encontros trabalharam a autoestima e a relação entre alunos. Nesses encontros foram utilizadas técnicas teatrais, principalmente a de se colocar no papel do outro (inversão de papeis). Percebeu-se grande facilidade e diversão com as técnicas, com as quais foi possível trabalhar temas considerados difíceis como preconceito, bullying e depressão.

No quinto e sexto encontros, para os temas de autoimagem e relação com a sociedade e a família, foram utilizadas técnicas de respiração e o uso da arte. Esses recursos se mostraram menos efetivos que os do teatro ou colagens. Por serem muito lúdicos e requerer introspecção e grande concentração, as discussões se mostraram mais empobrecidas.

Os três próximos encontros foram reservados para a temática do uso de álcool e outras drogas e foram realizadas rodas de conversa. Em dois encontros foram convidados alunos da UEMG que tinham conhecimento e facilidade com o tema, o que se mostrou de muita valia, pois os adolescentes se mostraram mais à vontade e de certa forma privilegiados pelas visitas.

Uma forma de abordar e saber as dúvidas quanto ao uso de álcool e outras drogas foi com o uso da tecnologia. Foi disponibilizado um site em que o aluno poderia postar suas dúvidas ou relatos de forma anônima para a equipe do projeto. As dúvidas eram respondidas e ajudaram a construir os grupos sobre o tema. 
No último encontro os alunos puderam escrever no quadro ou em papeis palavras que remetiam ao que aprenderam ou sentiram durante os encontros. As palavras "companheirismo"; "descontração"; "aprender"; "bate papo"; "diferente" apareceram com frequência.

Os alunos relataram que a experiência de aprendizado e troca de experiência em forma de roda de conversa ou com uso da arte foi efetiva, pois estariam "cansados" de aulas formais e palestras em que apenas ouviam e pouco eram escutados.

O projeto pretendeu e conseguiu atingir o objetivo de dar voz a esses adolescentes e entender mais suas vivências e realidades. Os resultados foram repassados e discutidos com a equipe pedagógica da escola.

Um dos limitadores do projeto foi o tempo, uma vez que em muitas ocasiões os encontros atrasavam devido a provas e outras atividades e em algumas ocasiões houve a presença de professores, o que pode ter inibido alguns alunos. Ao mesmo tempo a presença dos professores foi importante, apesar de causar constrangimento a alguns alunos, pois os mesmo relataram que levariam para a sala de aula muitas das técnicas e dinâmicas que observaram. Seria importante a realização de oficinas com esses profissionais para capacitá-los para a realização de grupos operativos no ambiente escolar.

\section{DISCUSSÃO}

O primeiro ponto a ser observado é quanto a formação de um laço com os participantes. Foi importante, pois as interações sociais e o se sentir parte de um grupo são fatores fundamentais quando se realiza intervenções com adolescentes. Para a efetividade das ações, os alunos precisavam se perceber como grupo social e aceitar os pesquisadores como parte dele, para que só assim uma troca de conhecimento e mudanças ocorressem (BECKER, 2017).

Como já relatado, o projeto inicial iria abordar apenas o uso de álcool e outras drogas, mas entendeu-se que o consumo de drogas por adolescentes não é fator isolado ou simples escolha pessoal, ela envolve fatores sociais e familiares, por isso a importância de se entender o contexto do adolescente e de fazê-lo compreender qual o seu papel nesse contexto (GONÇALVES et al, 2016).

Dentre as técnicas utilizadas, destaca-se o teatro como forma de se trabaIhar os temas drogas e bullying, pois através das representações lúdicas o adolescente se sente à vontade para ser outro indivíduo e se expressar livremente sobre temas considerados proibidos (LOPES, 2014).

Quanto a temas relacionados à escola e perspectivas de futuro, a equipe utilizou-se de imagens, colagens e rodas de conversa para apreender qual a visão desse adolescente. Dinâmicas que incentivavam o trabalho em grupo também foram propostas, pois uma das grandes dificuldades percebidas durante o projeto foi o trabalho em grupo. Os adolescentes apresentaram grande dificuldade em aceitar o trabalho de outros que não fossem de seu ciclo de amizade, fato esperado nessa faixa etária (GONÇALVES et al, 2013). 
A escola não foi percebida pelos adolescentes como local de promoção de saúde e aprendizagem, mas apenas como um local ao qual precisam ir por exigência da família e sociedade. Outros estudos também trazem essa realidade em que a escola está perdendo seu local como referência para os jovens, o que pode acarretar em aumento das faltas e abandono escolar, que são considerados fatores de risco para o uso de álcool e outras drogas (GARCÍA et al, 2008; MACHADO et al, 2015).

Outra dinâmica realizada que merece destaque foi a das "máscaras". Com essa dinâmica pretendia-se trabalhar aquilo que o adolescente apresenta para a sociedade como sendo seu "eu" e como isso pode diferenciar do que ele considera como o seu "eu verdadeiro". Para essa dinâmica foram levadas para a sala máscaras impressas no formato de rostos e em preto e branco. Os alunos foram orientados a enfeitar a máscara de um lado como sendo o modo como a sociedades os vêm, e do outro lado o modo como eles acreditam realmente ser.

Os adolescentes apresentaram muitas dúvidas e percebeu-se grande dificuldade em se expressarem através da arte. Pode-se considerar que o questionamento feito pelos coordenadores foi algo novo para muitos dos participantes. Mesmo aqueles que compreenderam a tarefa não conseguiram elaborar com clareza as faces da máscara.

Trabalhar o lúdico e fazer pensar é de extrema importância na sala de aula. Estudos demonstram que quando se trabalha educação em saúde de forma lúdica e abrangente o adolescente consegue associar melhor os temas apresentados e transformar em ação transformadora para seu dia-a-dia (LOPES, 2014). A grande dificuldade em se levar o lúdico para a sala de aula é a necessidade de mudanças que os educadores devem realizar em um sistema tradicional como o da educação, que acaba por engessar o professor ao conteúdo ministrado.

Quanto ao assunto do uso de álcool e outras drogas muitos adolescentes conheciam de maneira superficial os riscos do uso e tinham opinião clara do modo como a sociedade trata o uso de substâncias lícitas e ilícitas. Alguns afirmavam não ver o álcool como uma droga, pois seus efeitos, segundo os adolescentes, seriam mais tênues do que os de outras drogas. Visão corroborada em outros estudos que mostram que o álcool é aceito socialmente e, por conseguinte, tem o seu uso aumentado na adolescência, o que pode acarretar danos a curto e longo prazo (ANDRADE et al, 2017; COSTA et al, 2017).

As rodas de conversa sobre o tema propiciaram o esclarecimento de dúvidas sobre o funcionamento biológico das substâncias, as motivações para o uso, a proibição, e a possibilidade de interromper o uso, além da percepção de mudança de visão sobre o tema, principalmente sobre o uso do álcool.

\section{CONCLUSÃO}

Os grupos operativos se mostraram eficazes para abordar temas relacionados ao dia-a-dia do adolescente. Para se alcançar melhores resultados é necessário que projetos como esse sejam executados em longo prazo e que façam parte da rotina das escolas, com professores capacitados para a sua condução. 
Uma das questões levantadas pelos adolescentes foi a falta de espaço na escola para que eles se expressassem. O modelo tradicional de sala de aula também foi questionado como não favorecendo o aprendizado.

Assim, aulas mais dinâmicas, discussões em forma de roda ou com formatos mais lúdicos propiciam o aprendizado e principalmente a discussão de temas considerados tabus como droga e preconceito.

É necessário que a escola se reformule e dê espaço para seus alunos falarem, criando um ambiente prazeroso e de trocas de conhecimento.

\section{REFERENCIAS}

[1] Andrade, M. E, et al. Experimentação de substâncias psicoativas por estudantes de escolas públicas. Rev. Saúde Pública, vol. 51, 82, 2017. Disponível em: < https://www.scielosp.org/article/csc/2007.v12n5/1143-1154/ pt/\#ModalArticles >

[2] Barro A.; Mendes, A. M. O. C.; Barbosa, A. J. F. Programa de prevenção do uso/abuso de álcool para adolescentes em contexto escolar: parar para pensar. Esc. Anna Nery Rev. Enferm. vol. 17, n. 3, p. 466-73, 2013. Disponível em:<http://www.scielo.br/scielo.php?pid=\$1414-81452013000300466\&script=sci_abstract\&tlng=pt>

[3] Becker, K. L. O efeito da interação social entre os jovens nas decisões de consumo de álcool, cigarros e outras drogas ilícitas. Estud Econ. Vol. 47, n. 1, p. 65-92, 2017. Disponível em: <http://www.scielo.br/scielo. php?script=sci_arttext\&pid=S0101-41612017000100065\&lng=en\&nrm=iso>

[4] Cardoso, L. C.; MALBERGIER, A. Problemas escolares e o consumo de álcool e outras drogas entre adolescentes. Psicol. esc. educ. vol. 18, n.1, p.27-34, 2014. Disponível em: < http://www.scielo.br/scielo. php?script=sci_arttext\&pid=S1413-85572014000100003>

[5] Costa, A. C. Q. et al. Álcool e comportamento sexual entre estudantes do ensino médio no Brasil. Adolesc. Saude (online). vol. 14, n. 3, p.24-29, 2017. Disponível em: <http://www.adolescenciaesaude.com/detalhe_artigo. asp?id=668>

[6] Duarte, J. S. As contribuições da extensão universitária para o processo de aprendizagem, a prática da cidadania e o exercício profissional. Dissertação. Programa de Pós-graduação em Educação. Universidade Católica de Brasília. Brasília, 2014.

[7] Faria Filho, E. A et al. Concepções sobre drogas por adolescentes escolares. Rev. Bras. Enferm. Vol. 68, n. 3. p. 517-523, 2015. Disponível em: <http://www.scielo.br/scielo.php?script=sci_arttext\&pid=S003471672015000300517\&lng=en\&nrm=iso>.

[8] García, J. M. C.; Ferriani, M. G. C. A escola como "fator de proteção" para drogas: uma visão dos adolescentes e professores. Rev. Latinoam. enferm. Vol. 16, spe, p. 590-594,2008. Disponível em:< http://www. scielo.br/scielo.php?script=sci_arttext\&pid=\$0104-11692008000700014\&lng=en\&nrm=iso >

[9] Gonçalves, H. et al. Adverse childhood experiences and consumption of alcohol, tobacco and illicit drugs among adolescents of a Brazilian birth cohort. Cad. Saúde Pública (online). Vol. 32, n. 10, p. 00085815, 2016. Disponível em: < http://www.scielo.br/scielo.php?script=sci_arttext\&pid=S0102-311X2016001005009\&lng=en\&n $r m=i s o>$.

[10] IBGE, Instituto Brasileiro de Geografia e Estatística (Brasil). Pesquisa Nacional de Saúde do Escolar - PENSE 2015. Rio de Janeiro: IBGE; 2016.

[11] Locatelli, D et al. Socioeconomic influences on alcohol use patterns among private school students in São Paulo. Rev. Bras. Psiquiatr. Vol. 34, n. 2, p. 193-200, 2012. Disponível em: <http://www.scielo.br/scielo. 
php?script=sci_arttext\&pid=S1516-44462012000200012\&lng=en\&nrm=iso>

[12] Lopes, G. T. Percepções de adolescentes sobre uso/dependência de drogas: o teatro como estratégia pedagógica. Esc. Anna Nery. Rev. Enferm. Vol. 18, n. 2, p. 202-208, 2014. Disponível em: <http://www.scielo.br/ scielo.php?script=sci_arttext\&pid=S1414-81452014000200202\&lng=en\&nrm=iso>

[13] Machado, M. D. et al. Programa saúde na escola: estratégia promotora de saúde na atenção básica no Brasil. J. Hum. Growth Dev.. Vol. 25, n. 3, p. 307-312, 2015. Disponível em: <http://pepsic.bvsalud.org/scielo. php?script=sci_arttext\&pid=S0104-12822015000300009\&lng=pt\&nrm=iso>

[14] Malta, D. C. et al. Uso de substâncias psicoativas, contexto familiar e saúde mental em adolescentes brasileiros, Pesquisa Nacional de Saúde dos Escolares (PeNSE 2012). Rev. Bras. Epidemiol. suppl PeNSE. Vol. 17, supl. 1, p.46-61, 2014. Disponível em: <http://www.scielo.br/scielo.php?script=sci_arttext\&pid=\$1415-790X201400 0500046\&lng=pt\&nrm=iso\&tlng=pt>

[15] Moreira, A.; Lemos, V. C. M. D. Prevenção ao consumo abusivo de drogas na escola: desafios e possibilidades para a atuação do educador. Educ Pesqui.,. Vol. 41, n. 1, 2015. Disponível em: <http://www.scielo. br/scielo.php?script=sci_arttext\&pid=\$1517-97022015000100119\&lng=en\&nrm=iso>

[16] Strøm, H. K. et al Preventing alcohol use with a universal school-based intervention: results from an effectiveness study. BMC public health (online). Vol. 15, n. 1, 2015. Disponível em: <https://doi.org/10.1186/ S12889-015-1704-7>

[17] Vincha, K. R.; Santos, A. D.; Cervato-Mancuso, A. M. Planejamento de grupos operativos no cuidado de usuários de serviços de saúde: integrando experiências. Saúde debate. Vol. 41, m. 114p. 949-962, 2017. Disponível em: <https://www.scielosp.org/pdf/sdeb/2017.v41n114/949-962> 


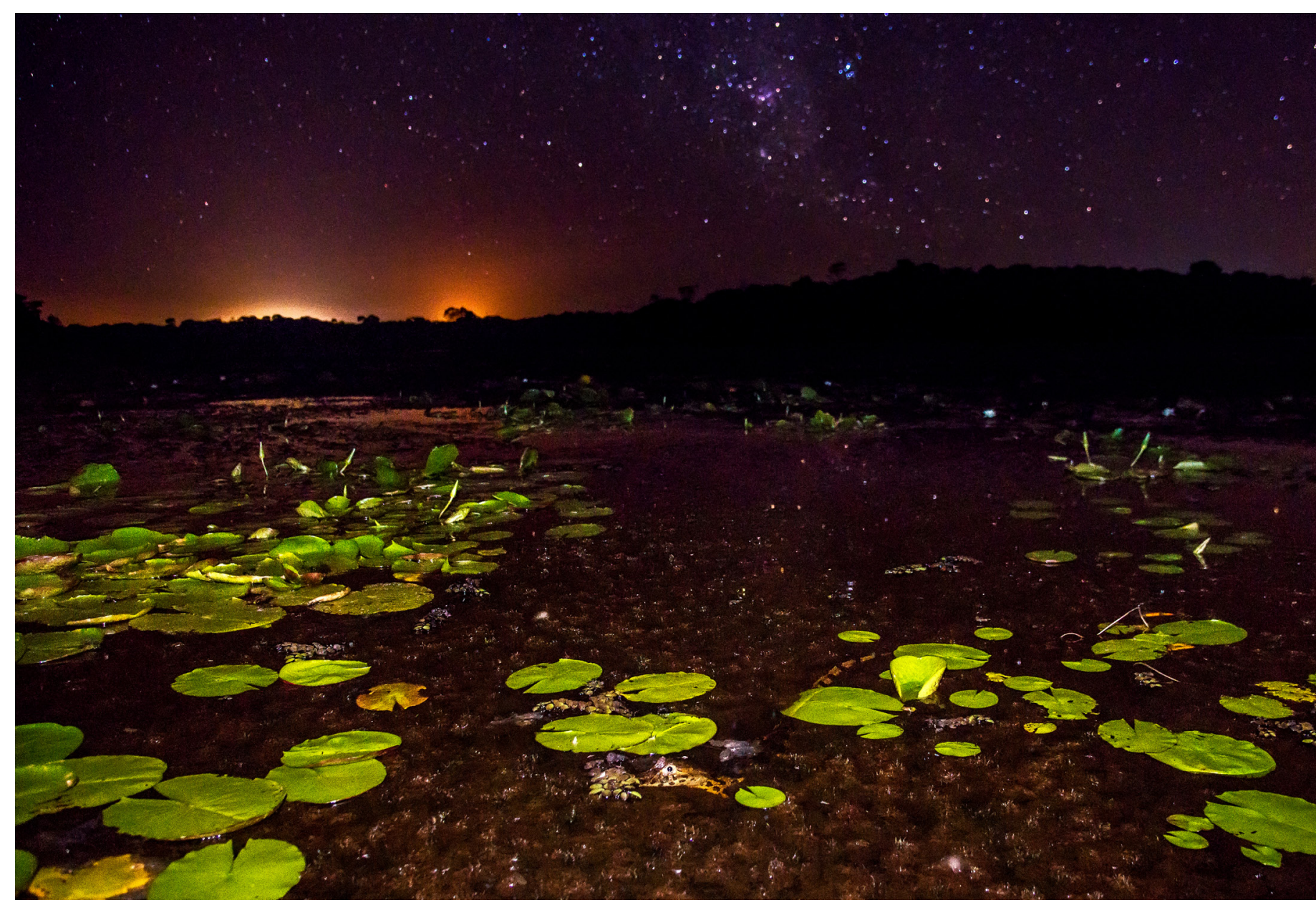

